\title{
Acute necrotizing glomerulonephritis associated with COVID-19 infection: report of two pediatric cases
}

\author{
Mitra Basiratnia $^{1} \cdot$ Dorna Derakhshan $^{1}$ (D) $\cdot$ Babak Shirazi Yeganeh $^{2} \cdot$ Ali Derakhshan $^{1}$
}

Received: 1 December 2020 / Revised: 22 December 2020 / Accepted: 11 January 2021 / Published online: 26 January 2021

(C) IPNA 2021

\begin{abstract}
Background Coronavirus disease 2019 (COVID-19) is thought to cause kidney injury via a variety of mechanisms. The most common reported kidney injury following COVID-19 infection is acute tubular injury (ATI); however, the procoagulant state induced by the virus may also damage the kidneys.

Case-diagnosis/treatment Herein, we report two cases of acute necrotizing glomerulonephritis (GN) with fibrinoid necrosis in the context of COVID-19 infection. The one with more chronic features in the kidney biopsy progressed to permanent kidney failure but the second one had an excellent response to glucocorticoid pulse therapy with subsequent normal kidney function at 2month follow-up.

Conclusions Both reported cases had an acute presentation of kidney injury with positive nasopharyngeal PCR test for COVID19. Based on the data review by the researchers, this is the first report of acute necrotizing GN associated with COVID-19 infection.
\end{abstract}

Keywords COVID-19 $\cdot$ Kidneys $\cdot$ Necrotizing glomerulonephritis $\cdot$ Dialysis $\cdot$ Pediatrics

\section{Introduction}

Kidney involvement is a common consequence of coronavirus 2019 (COVID-19) infection [1]. Several mechanisms have been proposed for acute kidney injury (AKI) following COVID-19 infection. The first and the most common is acute tubular injury (ATI) secondary to sepsis, hypovolemia, toxins, and cytokines. Second is the direct renal cell injury due to virus invasion. The third is the immune response dysregulation, which is evidenced by the presence of lymphopenia and cytokine release syndrome (cytokine storm) [2]. The fourth mechanism is related to the procoagulant state elicited by the virus which causes capillary obstruction and fibrinoid necrosis [3].

Although the most common reported kidney pathology attributed to COVID-19 is ATI, glomerular lesions including

Dorna Derakhshan

Dornaderakhshan@yahoo.com

1 Shiraz Nephro-Urology Research Center, Shiraz University of Medical Science, Shiraz, Iran

2 Pathology Department, Shiraz University of Medical Sciences, Shiraz, Iran collapsing glomerulopathy, pauci-immune crescentic GN, and segmental or global glomerulosclerosis have also been reported [4-8]. Herein, we present two cases of kidney damage secondary to COVID-19 who were admitted to the Pediatric Nephrology ward, Shiraz, Iran.

\section{Case 1}

A 17-year-old boy who was previously healthy presented to our referring hospital on October 10 2020, with a 2-week history of feeling unwell and a progressive decrease in urine output, nausea, and vomiting. He denied having fever, headache, and myalgia. At the referring hospital, he was found to have severe uremia with blood urea nitrogen (BUN) of $98 \mathrm{mg} /$ $\mathrm{dL}$ and serum creatinine $(\mathrm{Cr})$ of $10.8 \mathrm{mg} / \mathrm{dL}$ and was transferred to our center for further evaluation. The patient had an uneventful childhood and young adulthood with no history of prior admission or surgeries and was not taking any medications. Considering the COVID-19 pandemic, he did not have any close contact with an index case of COVID-19 nor had any travel to nearby cities or foreign countries. His family history was negative for any specific kidney problem or kidney failure. On initial physical examination, he was afebrile, 
hypertensive with a blood pressure (BP) of $155 / 90 \mathrm{mmHg}$, heart rate (HR) of $89 / \mathrm{min}$, and was mildly tachypneic with a respiratory rate (RR) of $32 / \mathrm{min}$. Oxygen saturation was $97 \%$ on room air. His anthropometric measurements revealed a weight of $65 \mathrm{~kg}$ (51.7th percentile), height of $189 \mathrm{~cm}$ (97.4th percentile), and body mass index of 18.2 (9th percentile). Relevant positive findings of the physical exam included drowsiness, bilateral mild periorbital edema, and bilateral basilar rales more prominent on the right side. Primary laboratory findings are listed in Table 1.

His urine output was $0.8 \mathrm{~mL} / \mathrm{kg} / \mathrm{h}$. Chest X-ray was significant for bilateral pleural effusion and pulmonary edema. Echocardiogram showed left ventricular (LV) hypertrophy with concomitant LV systolic and diastolic dysfunction. Kidney ultrasound revealed bilateral normal sized kidneys (right kidney $103 \mathrm{~mm}$; left kidney $100 \mathrm{~mm}$ ) with increased cortical parenchymal echogenicity. The patient emergently underwent hemodialysis for fluid overload and to correct the electrolyte imbalance. BP was controlled with furosemide, amlodipine, and carvedilol. His electrolyte imbalance was slowly corrected. Anemia was improved by an episode of packed cell transfusion followed by erythropoietin therapy. Considering the sustained respiratory findings of tachypnea and decreased oxygen saturation despite adequate daily dialysis and reversal of pulmonary edema and metabolic acidosis as well as the COVID-19 pandemic, a nasopharyngeal swab was sent for RT-PCR assay, which revealed a positive result. Following percutaneous kidney biopsy, he received 3 doses of methylprednisolone followed by $60-\mathrm{mg}$ oral daily prednisolone and an adjusted renal dose of enoxaparin along with

Table 1 Primary lab results of case 1 and case 2

\begin{tabular}{|c|c|c|}
\hline Lab data & Case 1 & Case 2 \\
\hline \multicolumn{3}{|l|}{ Biochemistry: } \\
\hline BUN & $150 \mathrm{mg} / \mathrm{dL}$ & $69 \mathrm{mg} / \mathrm{dL}$ \\
\hline $\mathrm{Cr}$ & $17 \mathrm{mg} / \mathrm{dL}$ & $15.6 \mathrm{mg} / \mathrm{dL}$ \\
\hline $\mathrm{Na}$ & $126 \mathrm{mg} / \mathrm{dL}$ & $135 \mathrm{mg} / \mathrm{dL}$ \\
\hline $\mathrm{K}$ & $4.4 \mathrm{mg} / \mathrm{dL}$ & $4.8 \mathrm{mg} / \mathrm{dL}$ \\
\hline $\mathrm{Ca}$ & $5.6 \mathrm{mmol} / \mathrm{L}$ & $9.5 \mathrm{mg} / \mathrm{dL}$ \\
\hline $\mathrm{P}$ & $12.5 \mathrm{mg} / \mathrm{dL}$ & $6.7 \mathrm{mg} / \mathrm{dL}$ \\
\hline Albumin & $4 \mathrm{~g} / \mathrm{dL}$ & $4 \mathrm{~g} / \mathrm{dL}$ \\
\hline Lactate dehydrogenase (LDH) & $957 \mathrm{U} / \mathrm{L}$ & $665 \mathrm{U} / \mathrm{L}$ \\
\hline CRP & $6 \mathrm{~g} / \mathrm{L}$ & $12 \mathrm{~g} / \mathrm{L}$ \\
\hline \multicolumn{3}{|l|}{ Hematologic lab results: } \\
\hline Hemoglobin & $5.1 \mathrm{~g} / \mathrm{dL}$ & $15.5 \mathrm{~g} / \mathrm{dL}$ \\
\hline $\mathrm{WBC}$ & $5100 \mathrm{~mm}^{3}$ (78\% neutrophils and $18 \%$ lymphocytes) & $\begin{array}{l}15300 \mathrm{~mm}^{3}(81 \% \text { neutrophils and } 16 \% \\
\text { lymphocytes }\end{array}$ \\
\hline Platelet count & $181,000 \mathrm{~mm}^{3}$ & $160,000 \mathrm{~mm}^{3}$ \\
\hline Peripheral blood smear & $\begin{array}{l}\text { Polymorphonuclear dominant WBC with severe } \\
\text { microcytic hypochromic anemia and less than } 1 \% \\
\text { fragmented RBCs. }\end{array}$ & $\begin{array}{l}\text { PMN dominant leukocyte with mild toxic } \\
\text { granulation, adequate platelet, and negligible } \\
\text { fragmented RBC }\end{array}$ \\
\hline Erythrocyte sedimentation rate (ESR) & $90 \mathrm{~mm} / \mathrm{h}$ & \\
\hline D-Dimer & Not provided & $3781 \mathrm{ng} / \mathrm{L}$ \\
\hline Urine examination & $\begin{array}{l}\text { Protein } 3+ \\
\text { Blood 3+ } \\
\text { RBC: many } \\
\text { Protein/Cr: } 0.56\end{array}$ & $\begin{array}{l}\text { Protein } 3+ \\
\text { Blood } 2+ \\
\text { Glucose } 2+ \\
\text { RBC: many } \\
\text { WBC: many }\end{array}$ \\
\hline \multicolumn{3}{|l|}{ Other lab results: } \\
\hline ASO titer & Negative & Negative \\
\hline Liver function tests & $\mathrm{Nl}$ & $\mathrm{N} 1$ \\
\hline Coagulation profile & $\mathrm{Nl}$ & $\mathrm{N} 1$ \\
\hline $\begin{array}{l}\text { Serologic studies including } \\
\text { ANA,DSDNA, P-ANCA, C-ANCA, } \\
\text { APL complements }\end{array}$ & $\mathrm{Nl}$ & $\mathrm{N} 1$ \\
\hline
\end{tabular}

$A S O$, antistreptolysin $\mathrm{O} ; A N A$, antinuclear antibodies; $D S D N A$, double-stranded DNA; $P$-ANCA, perinuclear anti-neutrophil cytoplasmic antibodies; $C$ $A N C A$, cytoplasmic anti-neutrophil cytoplasmic antibodies; $A P L$, anti-phospholipid antibodies; $N l$, normal 

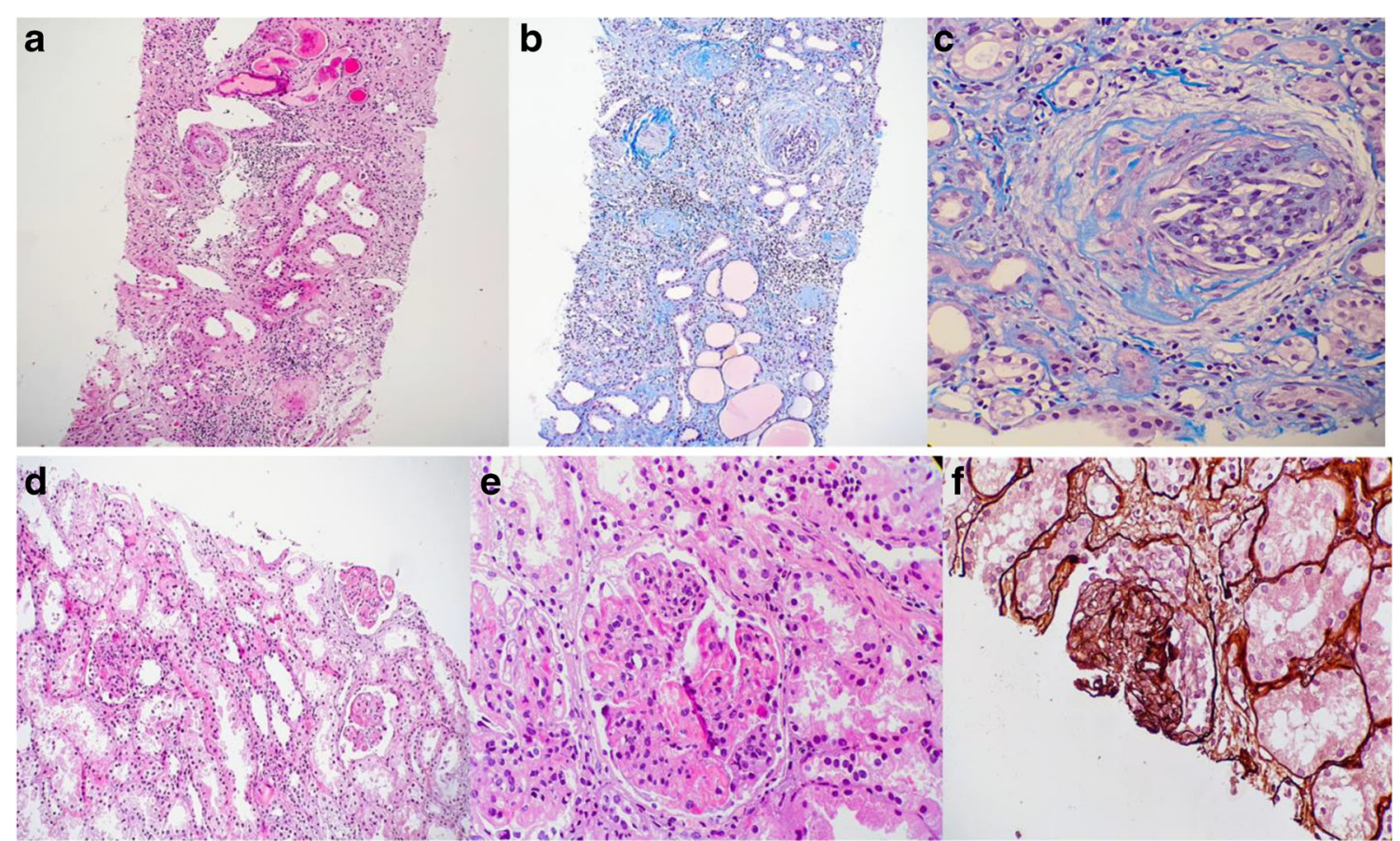

Fig. 1 Kidney biopsy specimens of cases 1 and 2. a Case 1: Thickening of the arteriolar wall, tubular atrophy, and global sclerosis of glomeruli (H\&E stain, original magnification $\times 100$ ); b Case 1 : Diffuse global sclerosis of glomeruli, moderate tubular atrophy and intertubular hyaline casts, severe interstitial fibrosis, arteriolar wall thickening with intimal fibrosis (Masson trichrome stain original magnification $\times 100$ ); $\mathbf{c}$

hemodialysis. Considering the positive COVID-19 nasopharyngeal swab and acute onset of kidney involvement, urine and kidney tissue PCR assays for COVID-19 were also done, both of which revealed negative results.

High-resolution computed tomography (HRCT) of the chest after adequate hemodialysis revealed bilateral basilar congestion which could be indicative of COVID-19 lung involvement.

Light microscopy of the kidney biopsy revealed acute necrotizing glomerulonephritis with $1 / 9$ fibrocellular crescents leading to diffuse global glomerulosclerosis ( 8 of 9 glomeruli were sclerotic), severe acute tubulointrestitial nephritis with $60 \%$ tubular atrophy with interatubular hyaline casts and about $40 \%$ interstitial fibrosis. Arterioles also showed thickening of the wall with fibrinoid necrosis (Fig. 1). The immunofluorescence was negative. Unfortunately, his kidney function did not recover during the 2 weeks' duration of admission. Thus, a permanent subclavian catheter was inserted for routine hemodialysis and prednisolone was tapered off in follow-up.

\section{Case 2}

The patient was a 16-year-old boy who was admitted to our pediatric nephrology ward due to acute onset of fever,
Case 1: Glomerulus with fibrocellular crescent (Masson trichrome stain, original magnification $\times 400$ ); $\mathbf{d}$ Case 2: 3 glomeruli with necrosis and proliferation (H\&E stain, original magnification $\times 100)$; e Case 2 : Glomerulus with severe hypercellularity, segmental necrosis and PMN infiltration; f Case 2: Cellular crescent formation (Jones silver stain original magnification $\times 400$ )

oliguria, and tea colored urine since 5 days prior to his admission on 22 September 2020. The patient had been completely healthy until 5 days before admission with symptoms of fever, chills, nausea and vomiting followed by oliguria, and tea color urine. He was admitted to another center and was transferred to our hospital due to a severe rise in BUN and $\mathrm{Cr}(70 \mathrm{mg} / \mathrm{dL}$ and $15.5 \mathrm{mg} / \mathrm{dL}$ respectively). His past medical history was not significant except for an episode of gastroenteritis and fever 1 month before his admission. He also had a routine checkup including kidney function and complete blood count 5 months before, all of which were normal. His family history was negative for any relevant disease. He denied taking any recent medication.

On physical examination, the patient was mildly lethargic without significant respiratory distress but had periorbital edema. His axiological parameters were within normal limits (weight of $50 \mathrm{~kg}$ (10.8th percentile); height of $169 \mathrm{~cm}$ (100th percentile)). His vital signs included a temperature of $37.1^{\circ} \mathrm{C}$, HR of $84 / \mathrm{min}$, RR of $26 / \mathrm{min}$, and BP of $130 / 70$ $\mathrm{mmHg}$. The rest of the physical examinations were normal. Initial hospital lab data are summarized in Table 1. The nasopharyngeal swab RT-PCR assay was positive for COVID-19 while the urine specimen result was negative. After primary stabilization, a double lumen catheter was inserted for him and the patient underwent two episodes of hemodialysis. In addition, he received 3 pulses of methylprednisolone on 
consecutive days, followed by $60 \mathrm{mg}$ oral prednisolone and daily subcutaneous injection of enoxaparin. HRCT of the lungs showed bilateral ground glass opacities. The kidney biopsy result revealed 7 glomeruli with active necrotizing proliferative glomerulonephritis accompanied by infiltration of polymorphonuclear leukocytes, as well as focal crescent formation in 1 glomerulus which was prominent on Jones silver stain. The tubular interstitium and vessels were completely unremarkable (Fig. 1).

Fortunately, the patient's general condition improved; urine output increased to the normal volume and serum $\mathrm{Cr}$ decreased gradually to $0.8 \mathrm{mg} / \mathrm{dL}$ in follow-up visits. Kidney tissue assessment for the presence of COVID-19 indicated a negative result. After 2 months, the patient had normal urine analysis and kidney function, and steroid was discontinued.

\section{Discussion}

The recent pandemic of COVID-19 affects all ages but children have substantially less severe clinical presentations than adults [9]. The main clinical findings in children are upper and lower respiratory tract symptoms but other organ systems may also be affected following the infection [1]. Various forms of kidney involvement have been reported in children in the context of COVID-19 infection. AKI is the most prevalent but there are also two recent reports of association of COVID-19 infection and nephrotic syndrome in children $[10,11]$.

The common kidney pathologies following COVID-19 infection include ATI $[7,8]$, direct renal cell invasion by the virus, immune dysregulation (initiated by systemic cytokine activation) [2, 8], and thrombotic microangiopathy [3-11]. Various patterns of glomerular injury have been described associated with COVID-19 infection in adult studies. Collapsing FSGS is the more prevalent reported glomerular lesion, which is mostly reported in African-American ethnicity and has been attributed to APO-L1 genotype [8]. ANCApositive crescentic GN is another observed glomerular lesion and has been reported from the USA and Iran $[12,13]$.

Both of our cases had acute necrotizing GN with clear evidence of fibrinoid necrosis that coincided with COVID19 infection. However, the first patient had profound anemia, and several sclerotic lesions that implicated a prior established chronic kidney disease (CKD) with acute exacerbations following COVID-19 infection. However, the normal kidney size and normal growth indices were contrary to general findings in CKD.

Neither of our patients had viruria and they both had negative RT-PCR for COVID-19 RNA on kidney tissue specimens. We believe the presence of fibrinoid necrosis in the kidney biopsy spotlights the possibility of the virus-induced procoagulant state. Hence, we considered adjusted renal dose of enoxaparin in both patients along with steroid pulse therapy after primary stabilization and hemodialysis. Neither of our patients received specific antiviral treatment for COVID-19 as they both had predominant kidney presentations, and only case 1 had mild respiratory problems which responded well to supportive therapy. Our first patient was discharged with a prescription of routine hemodialysis but the second had a more satisfactory course responding well to glucocorticoid therapy with subsequent improvement in kidney function.

In conclusion, glomerular lesions may be encountered following COVID-19 infection. To the best of our knowledge, our patients are the first cases of acute necrotizing GN with fibrinoid necrosis in the context of COVID-19 infection in the pediatric population. However, we could not definitively clarify a coincidence or an unusual form of presentation of COVID-19. Pediatric nephrologists should be aware of this rare presentation during the pandemic.

Authors' contributions $\mathrm{MB}$ and $\mathrm{AD}$ made the final diagnosis and carried out the therapeutic measures. DD drafted the manuscript. BSH provided the pathologic reports and figures. All authors read and approved the final version of the manuscript.

\section{Compliance with ethical standards}

Competing interests The authors declare that they have no competing interests.

\section{References}

1. Naicker S, Yang CW, Hwang SJ, Liu BC, Chen JH, Jha V (2020) The novel coronavirus 2019 epidemic and kidneys. Kidney Int 97: 824-828

2. Ronco C, Reis T, Husain-Syed F (2020) Management of acute kidney injury in patients with COVID-19. Lancet Respir Med 8: 738-742

3. Gagliardi I, Patella G, Michael A, Serra R, Provenzano M, Andreucci M (2020) Covid-19 and the kidney: from epidemiology to clinical practice. J Clin Med 9:2506

4. Golmai P, Larsen CP, DeVita MV, Wahl SJ, Weins A, Rennke HG, Bijol V, Rosenstock JL (2020) Histopathologic and ultrastructural findings in postmortem kidney biopsy material in 12 patients with AKI and COVID-19. J Am Soc Nephrol 31:1944-1947

5. Larsen CP, Bourne TD, Wilson JD, Saqqa O, Sharshir MA (2020) Collapsing glomerulopathy in a patient with COVID-19. Kidney Int Rep 5:935-939

6. Peleg Y, Kudose S, D’Agati V, Siddall E, Ahmad S, Nickolas T, Kisselev S, Gharavi A, Canetta P (2020) Acute kidney injury due to collapsing glomerulopathy following COVID-19 infection. Kidney Int Rep 5:940-945

7. Sharma P, Uppal NN, Wanchoo R, Shah HH, Yang Y, Parikh R, Khanin Y, Madireddy V, Larsen CP, Jhaveri KD, Bijol V, Northwell Nephrology COVID-19 Research Consortium (2020) COVID-19-associated kidney injury: a case series of kidney biopsy findings. J Am Soc Nephrol 31:1948-1958

8. Wu H, Larsen CP, Hernandez-Arroyo CF, Mohamed MMB, Caza T, Sharshir M, Chughtai A, Xie L, Gimenez JM, Sandow TA, Lusco MA, Yang H, Acheampong E, Rosales IA, Colvin RB, 
Fogo AB, Velez JCQ (2020) AKI and collapsing glomerulopathy associated with COVID-19 and APOL1 high-risk genotype. J Am Soc Nephrol 31:1688-1695

9. Badal S, Bajgain KT, Badal S, Thapa R, Bajgain BB, Santana MJ (2020) Prevalence, clinical characteristics, and outcomes of pediatric COVID-19: a systematic review and meta-analysis. J Clin Virol 135:104715

10. Alvarado A, Franceschi G, Resplandor E, Sumba J, Orta N (2021) COVID-19 associated with onset nephrotic syndrome in a pediatric patient: coincidence or related conditions? Pediatr Nephrol 36:205207. https://doi.org/10.1007/s00467-020-04724-y

11. Shah SA, Carter HP (2020) New-onset nephrotic syndrome in a child associated with COVID-19 infection. Front Pediatr 8:471
12. Moeinzadeh F, Dezfouli M, Naimi A, Shahidi S, Moradi H (2020) Newly diagnosed glomerulonephritis during COVID-19 infection undergoing immunosuppression therapy, a case report. Iran J Kidney Dis 14:239-242

13. Uppal NN, Kello N, Shah HH, Khanin Y, De Oleo IR, Epstein E, Sharma P, Larsen CP, Bijol V, Jhaveri KD (2020) De novo ANCAassociated vasculitis with glomerulonephritis in COVID-19. Kidney Int Rep 5:2079-2083. https://doi.org/10.1016/j.ekir.2020. 08.012

Publisher's note Springer Nature remains neutral with regard to jurisdictional claims in published maps and institutional affiliations. 